\title{
Versatile Psychophysiological Potencies of Essential Oils, when Seen as a Function of Behavioral Task Assigned to the Participants after Inhalation
}

\author{
Yoshiaki Sugawara ${ }^{1}$, Asami Shigetho ${ }^{1}$, Mai Yoneda ${ }^{1}$, Tomoko Tuchiya ${ }^{1}$, \\ Hiroko Yamada $^{1}$, Tomomi Matumura ${ }^{1} \&$ Miki Hirano $^{1}$ \\ ${ }^{1}$ Department of Health Science, Prefectural University of Hiroshima, Hiroshima, Japan \\ Correspondence: Yoshiaki Sugawara, Prefectural University of Hiroshima, Hiroshima, 1-1-71 Ujina-higashi, \\ Minami-ku, 734-8558, Japan.
}

Received: September 14, 2015

Accepted: September 28, 2015

Available online: October 7, 2015

doi:10.11114/ijsss.v3i6.1129

URL: http://dx.doi.org/10.11114/ijsss.v3i6.1129

\begin{abstract}
To elucidate the psychophysiological effect of inhaling essential oils, in this paper, we sought to assess the following 12 essential oils: basil, bergamot, cardamom, cinnamon, juniper, lemon, orange, palmarosa, peppermint, sandalwood, spearmint, and ylang ylang. As these being target odors, we focused on the verbal (semantic) and non-verbal (skin temperature) endpoints of the stimuli. In our experimental design, we managed to assign different behavioral tasks to the participants. The Uchida-Kraepelin test was used as a mental arithmetic task and listening to environmental (natural) sounds as an auditory task. In the verbal study, for an example, we conducted the sensory test twice, once before and once after the task. As a measure of the perceived odor quality in participants after inhalation of a given aroma, we employed a sensory evaluation spectrum. It is a bar graph in which the mean of the difference in score between pre- and post-task inquiry (post minus pre) was plotted against the impression descriptors. Taking into account of the obtained skin temperature changes between pre- and post-task inhalations, the subtle nuances between verbal and non-verbal expressions seen as a function of the two behavioral tasks assigned to the participant suggested that essential oils may have versatile psychophysiological potencies by the nature.
\end{abstract}

Keywords: behavioral tasks, essential oils, psychophysiological potencies, sensory test, skin temperature measurement

\section{Introduction}

The scent of different odors is known to alter mood, alertness, and sexual arousal (Billot \& Wells, 1975; Morris, 1984; Valnet, 1982). Perfumes, room fragrances, and incense have been used for self-adornment and modification of living spaces since ancient times. The practice known as Aromatherapy, which began in France in the early 20th century, has been increasing in popularity up to the present day. In medicine, interest in the use of essential oils has grown considerably, such that essential oils are currently used worldwide for the management of chronic pain, depression, anxiety, and cognitive, sleep-, and stress-related disorders (Buchbauer \& Jirovetz, 1994; Buckle, 1999, 2004; Edge, 2003; Holmes et al., 2002; Jimbo et al., 2009; Kyle, 2006; Lin et al., 2007; Perry \& Perry, 2006; Price \& Price, 2007; Smallwood et al., 2001). Essential oils are now extensively utilized in the context of alternative medicine, specifically aromatherapy, and aroma wellness.

The following questions arise: How does the brain prompt the range of emotional or behavioral responses that aromas often provoke? To what extent is a particular behavior or mood governed by the perception of odors? In a series of studies, we have attempted to examine the relationship between mood change, odor and its psychophysiological responses, by focusing on the possible verbal (semantic) and non-verbal (skin temperature) changes in humans induced by smelling the fragrances of essential oils as well as linalool and its enantiomers (Satoh \& Sugawara, 2003; Sugawara, 2001, 2008; Sugawara \& Kawasaki, 2000; Sugawara et al., 1998a, 1998b, 1999, 2000, 2003, 2006, 2008, 2009, 2013, 2015; Yamagata \& Sugawara, 2014).

In this article, we present an overview of our latest verbal and non-verbal research results whereby attention was focused on the following 12 essential oils: basil (Ocimum basilicum), bergamot (Citrus bergamia), cardamom (Elettaria cardamomum), cinnamon (Cinnamomum zeylanicum), juniper (Juniperus communis), lemon (Citrus limon), orange (Citrus sinensis), palmarosa (Cymbopogon martini), peppermint (Mentha piperita), sandalwood (Santalum album), spearmint (Mentha spicata), and ylang ylang (Cananga odorata). Because the obtained subtle nuances of expressions between 
verbal and non-verbal effects after inhalation of the tested odors, when seen as a function of behavioral task assigned to the participants, suggested that essential oils may have versatile psychophysiological potencies by the nature.

In this research, we conducted two experiments: in one, participants completed a verbal (semantic) task during differential discrimination of the perceived odor quality of a given aroma; and in the other, we conducted a non-verbal (fingertip skin temperature) investigation to probe the physiological effects of the tested odors. In both studies, we assigned behavioral tasks to the participants. These included the Uchida-Kraepelin test as a mental arithmetic task and listening to environmental (natural) sounds as an auditory task. In our experimental design, the verbal tests always antedated the non-verbal tests because the verbal tests were used to screen the essential oils that would be used in the non-verbal investigations.

In our antedated verbal tests, we asked the participants to complete a sensory questionnaire in which the perceptions of fragrances were evaluated using 13 contrasting pairs of adjectives. The sensory test was conducted twice, once before and once after the task. We then represented the sensory attributes of the perceived odors of the essential oils before and after the task via a sensory spectrum: a bar graph whereby the mean of the impressions was plotted against the semantic impression descriptors. Accordingly, the sensory attributes of 21 essential oils were compiled in relation to the three different behavioral tasks (i.e., the above-mentioned two tasks plus stepping up and down a step as a physical task), in which beyond the above-mentioned 12 examples, we measured the sensory attributes of chamomile (Matricaria chamomilla), clove (Syzygium aromaticum), cypress (Cupressus sempervirens), geranium (Pelargonium graveolens), ho leaf/wood (Cinnamomum camphora), lavender (Lavandula angustifolia), lime (Citrus latifolia), marjoram (Origanum majorana), and rosemary (Rosmarinus officinalis) (Sugawara et al., 2013, 2015; Yamagata \& Sugawara, 2014).

After that, we employed multi-channel skin (fingertip) temperature measurements as a non-verbal procedure and commenced to probe the possible physiological effect of inhaling essential oils. The measurements were carried out on the 21 essential oils one by one as a function of the three different behavioral tasks. As the study progressed, however, we decided to concentrate on two tasks (the mental arithmetic task and the auditory task), and narrowed our focus to involve only the aforementioned 12 essential oils.

Conclusively, as an example of representative of our experiments, we found that skin temperature response to the lemon fragrance produced contrasting changes during the two behavioral tasks: we measured a significant decrease in skin temperature between pre- and post-task inhalations during mental arithmetic (at $p<0.05$ ), and a significant increase in skin temperature during the auditory task (at $p<0.05$ ). Additionally, independent inhalation of bergamot, peppermint, sandalwood, and ylang ylang elicited a decrease in skin temperature during the two tasks, however, these fragrances were associated with contrasting sensory spectra. Thus, the subtle nuances of expression between the verbal and non-verbal effects in relation to different behavioural tasks suggested that versatile psychophysiological potencies could be the nature of the tested odors. Moreover, the tested odors seemed to function as neurophysiological stimuli that can cause different perception and elicit diverse reactions, depending on the internal and extraneous conditions of the participants, as well as manifestations of higher-order olfactory processing.

Based on these findings in the background, in this paper, we aim to achieve a close consensus on the issue that essential oils may have versatile psychophysiological potencies, and can produce versatile and inherent psychophysiological effects. Although psychological (verbal) and physiological (non-verbal) endpoints of the stimuli are rarely reported in the same study, we believe that this approach has the potential to be highly informative.

\section{Method}

\subsection{Verbal (Semantic) Tests that Preceded the Non-Verbal Investigation}

Essential oils were purchased from Fleur (London, UK). In the inhalation experiments, we used the following dilutions: 1/5 for lemon; 1/10 for bergamot, cardamom, cinnamon, juniper, orange, palmarosa, sandalwood, spearmint, and ylang ylang; and 1/100 for basil, and peppermint.

To achieve the optimal concentration mentioned above, we conducted preliminary sensory tests according to the methods described in Sugawara et al. (1999). We presented a series of diluted solutions, which comprised the odorants mixed with deodorized diethyl phthalate $(1 / 1,1 / 5,1 / 10,1 / 50,1 / 100,1 / 1,000$, and $1 / 10,000)$, to several judges (usually five) via an inhalator consisting of a glass inhalator device and a $300-\mathrm{mL}$ flask with a ground-glass stopper. The inhalator flask was loaded by applying $200 \mu \mathrm{L}$ of diluted odorant to a small strip of filter paper placed at the bottom of the flask. The flask was sealed with the ground-glass stopper. The judges were asked to give each test solution a score from 0 to 5 based on the following scale: 0 , odorless; 1 , odor barely detectable and the nature of the odor cannot be ascertained; 2 , very weak odor but the nature of the odor can be discriminated; 3 , weak odor but the odor can be readily detected; 4, strong odor; and 5, odor so strong that it cannot be tolerated. Concentrations receiving a score of 3 or above were used for experiments. 
Lorig and Schwartz (1988) stated that odors act as neurophysiological stimuli by causing different perceptions, which, in turn, lead to diverse odor reactions, depending on the internal and extraneous conditions of the participants. To investigate this notion, we assigned different behavioral tasks ("extraneous conditions") to the participants. We used the Uchida-Kraepelin test as a mental arithmetic task, listening to environmental (natural) sounds as an auditory task, and stepping up and down a step as a physical task. In the Uchida-Kraepelin test, the participant is given a sheet of paper with adjacent rows of numbers (100 numbers per row). They are asked to perform simple additions using the numbers within a row. We gave our participants $40 \mathrm{~s}$ to work on each row before changing to the next row ( 5 min total). The auditory task ( 5 min total) consisted of sitting on a chair and listening to natural sounds, such as birds singing and the murmuring of a small stream. This was accomplished via headphones connected to a compact disc player. The physical task involved stepping up and down a 20 -cm step at a rate of 30 times per min for $5 \mathrm{~min}$.

As a measure (sensory profiling) of the perceived odor quality after inhalation of a given aroma, we asked the participants to complete a sensory questionnaire assessment (Sugawara, 2008; Sugawara et al., 2009, 2013, 2015; Yamagata \& Sugawara, 2014). In the questionnaire, aroma perception was evaluated using 13 descriptors comprising the following pairs of contrasting adjectives: fresh-stale, soothing-activating, airy-heavy, plain-rich, natural-unnatural, elegant-unrefined, soft-strong, pleasant-unpleasant, warm-cool, comfortable-uncomfortable, woodsy-not woodsy, floral-peppery, lively-dull.

The 13 descriptors were scored on an 11-point scale $(-5$ to +5$)$, with 0 as the middle score. There were no symbolic representations associated with the numbers, similar to the Likert scale (Likert, 1932). We conducted the sensory test twice, before and after the task. We evaluated the differences between the pre- and post-task scores (post-task scores minus pre-task scores) for each of the descriptors using Student's $t$-tests. The mean difference in the score of each descriptor was plotted against the 13 descriptors, producing a sensory evaluation spectrum. The statistical significance of each descriptor was marked and scored as follows: a score was given an * (asterisk) and a significance score of 1 if the difference was significant such that $p<0.05 ; \mathrm{a} \pm$ and a significance score of 0.5 if the difference was significant such that $p=0.05-0.1$; and no symbol and a significance score of 0 if the difference was not significant such that $p \geq$ 0.1 . The sum of these scores was the total significance score $=\Sigma_{i=1}^{13}{ }_{i=1}$ (significance score of descriptor) ${ }_{i}$.

Figure 1 shows a summary of the responses of the participants after inhalation of the fragrances of essential oils of lemon and ylang ylang in association with either mental arithmetic or the auditory task. The sensory spectrograph obtained after inhalation of lemon in association with the mental arithmetic task indicates an unfavorable (downward or negative) correlation between the fragrance and the task (Figure 1a). On the other hand, the spectrograph after inhalation of lemon in association with the auditory task denotes that half of the significant descriptors were positive and the other half negative (Figure 1c). In turn, negative (unfavorable) correlation similar to the spectrograph for lemon/mental arithmetic (Figure 1a) was in view in the spectrograph of ylang ylang/mental arithmetic (Figure 1b). In contrast, positive (favorable) correlation between the fragrance and the task was obvious in the spectrograph of ylang ylang/auditory task (Figure 1d). This means that the sensory attribute after inhalation of the fragrance of ylang ylang produced opposite (contrasting) signs during the two behavioral tasks in terms of the sensory evaluation spectrum (Figure $1 \mathrm{~b}$ and $\mathrm{d}$ ). One was representing downward spectrograph in relation to the mental arithmetic task and the other representing upward spectrograph in association with the auditory task. It seemed that different behavioral tasks (or different "extraneous conditions") might influence the perceived odor quality of a given aroma after inhalation. In other words, that the finer nuances were visible in each spectrum when observed as a function of the different behavioral tasks indicated that this method of sensory profiling could be practical for assessing odor perception in participants.

In our experimental design, in each spectrograph (as shown in Figure 1), the statistical significance of each descriptor was marked and scored as follows: * (asterisk) and significance score of 1 if the difference was significant such that $p<$ $0.05 ; \pm$ and a significance score of 0.5 if the difference was significant such that $p=0.05-0.1$; and no symbol and a significance score of 0 if the difference was not significant such that $p \geq 0.1$. The sum of these scores provided a total significance score $=\Sigma^{13}{ }_{i=1}$ (significance score of descriptor $)_{\mathrm{i}}$. Total significance scores were calculated by simple addition of the statistical significance scores marked on the individual descriptors in the relevant spectrum. In Figure 1a-d, we obtained total significance scores of 8.0 for lemon/mental arithmetic, 7.0 for lemon/auditory task, 2.0 for ylang ylang/mental arithmetic, and 5.5 for ylang ylang/auditory task.

As a result of our verbal tests that preceded the non-verbal tests, we were able to establish appropriate parameters for assessing the sensory attributes of the following 21 essential oils, and linalool and its enantiomers $((R)-(-)-,(S)-(+)-$ and $(R S)$-( \pm )-forms) as a function of the three behavioral tasks (mental arithmetic, auditory, and physical): basil, bergamot, cardamom, chamomile, cinnamon, clove, cypress, geranium, ho leaf/wood, juniper, lavender, lemon, lime, marjoram, orange, palmarosa, peppermint, rosemary, sandalwood, spearmint, and ylang ylang (Sugawara et al., 2013, 2015; Yamagata \& Sugawara, 2014). 
To this end, 1,631 participants formed the sensory test panel. Among these, 90 were male students from Hiroshima University ranging in age from 18 to 24 years. The remaining participants were female students at Hiroshima University, Prefectural University of Hiroshima (formerly Hiroshima Prefectural Women's University, but renamed as of April 1, 2005) and Suzugamine Women's College, ranging in age from 18 to 22 years. Thus, the proportion of male participants was only about $5 \%$. Each participant completed one sensory profile only.

(a) Lemon/ Mental arithmetic

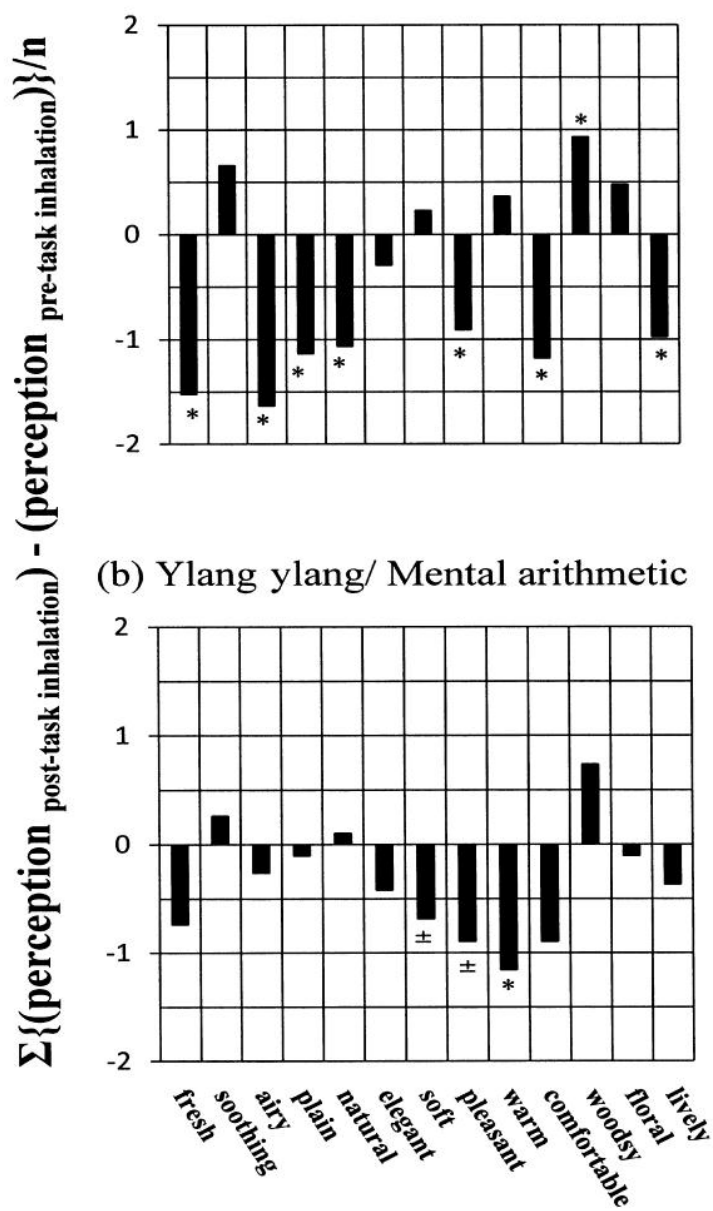

(c) Lemon/ Auditory task

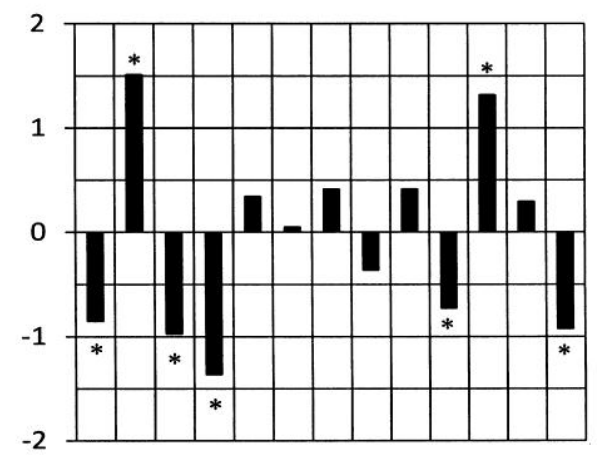

(d) Ylang ylang/ Auditory task

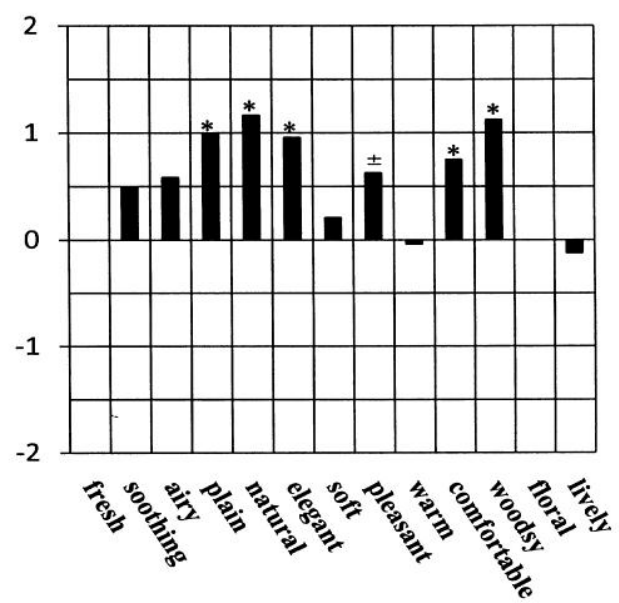

Figure 1. Task (i.e., mental arithmetic task and the auditory task) dependent changes of the perceived odor quality of the participants following inhalation of essential oils of lemon and ylang ylang in terms of sensory spectrograph. A sensory test was conducted twice before and after the task, in which aroma perception was evaluated by 13 impression descriptors consisting of contrasting pairs of adjectives. The pre-post task difference in the score of each of the impression descriptors is plotted on the ordinate as a bar graph (sensory spectrograph). The statistical significance evaluated by $t$-test of each descriptor was marked with a single asterisk $(*)$ if the pre-post impression difference was regarded significant with $p<0.05, \pm$ if regarded significant with $p=0.05-0.1$, and unmarked if $p \geq 0.1$. The number of participants was (a) 43, (b) 19, (c) 41 and (d) 24.

\subsection{Use of a Multi-Channel Skin Thermomerter as a Non-Verbal Measure}

As a non-verbal way to investigate the physiological effect of inhaling essential oils, we conducted multi-channel skin thermometer measurements in a climatic chamber maintained at $20{ }^{\circ} \mathrm{C}$ and $60 \%$ relative humidity. A total of 415 participants completed the study. Participants were all female students at Prefectural University of Hiroshima, ranging in age from 18 to 22 years. The procedure was first explained to each participant, who were then encouraged to relax and allowed to rest quietly for $5 \mathrm{~min}$ before the test began. None of the participants were suffering from any chronic diseases, nasal congestion, or upper respiratory tract infections, and no participants were taking any medication, remedies, or contraceptive pills. To avoid the potential confounding effects of hormonal profile and physiological status, female participants did not participate in the study during menses. Ambient noise was kept at a low level (30-40 dBA) during the experiments. 
We recorded skin temperature (fingertip) using a thermometer (Anritsu AM-7052; Anritsu Meter Co., Tokyo, Japan) equipped with a multi-channel data collector. Thin surface thermistors $(2 \times 10 \mathrm{~mm})$ were used as sensors. They were attached with adhesive tape to the tips of all fingers on the left hand and to the palm at the base of the first finger of the left hand.

Various parts of the body have different temperatures that undergo circadian fluctuations. Thus, we conducted a pilot experiment in which the thermistors were affixed to the left cheek, left earlobe, forehead, tip of the left first finger, left palm (at the base of the first finger), and back of the left hand (at the base of the first finger). We used an odorless blank as a negative control. The skin temperature curve obtained from the tip of the left first finger and left palm showed a small but significant increase after odor inhalation, while practically no change was observed at the other measurement points (Sugawara \& Kawasaki, 2000). Therefore, we developed a multi-channel thermometric technique by which skin temperature could be measured from the fingertips and palm of the left hand (Satoh \& Sugawara, 2003; Sugawara et al., 2006, 2008, 2009, 2013, 2015).

All data were stored on a personal computer at a sampling rate of $15 \mathrm{~s}$ via an A/D converter connected to the multi-channel thermometer. This allowed summation of the data from each channel every $15 \mathrm{~s}$ so that a single temperature curve could be obtained for the six measurement points. The experimental protocol was as follows: (1) inhalation of the odorless blank (total inhalation: 3 min; presence of the odorless blank: $30 \mathrm{~s}$ ), (2) inhalation of the essential oil before the task (total: $5 \mathrm{~min}$, presence of the fragrance: $1 \mathrm{~min}$ ), (3) $5 \mathrm{~min}$ of the task, (4) post-task inhalation of essential oil (total: $5 \mathrm{~min}$; presence of the fragrance: $1 \mathrm{~min}$ ), and (5) inhalation of the odorless blank (total: 3 min; presence of the odorless blank: $30 \mathrm{~s}$ ).

For each experimental run, we constructed a temperature profile (bar chart) by integrating the temperature curves (per minute) with each section of the skin temperature measurement protocol (mean temperatures at 1-minute intervals). We were then able to calculate the net skin temperature change between the presentation of the odorless blank and the presentation of the target fragrance: $\left(\mathrm{T}^{\mathrm{MMA}}{ }_{\text {odor }}-\mathrm{T}^{\mathrm{MMA}}{ }_{\mathrm{o}}\right) / \mathrm{T}^{\mathrm{MMA}}{ }_{0}$, where $\mathrm{T}^{\mathrm{MMA}}$ odor is the mean minute-based average temperature during odor presentation, and $\mathrm{T}^{\mathrm{MMA}}{ }_{\mathrm{o}}$ is the intensity during the presentation of the odorless blank.

Figure 2 shows an example of skin temperature study from a subject who inhaled lemon before and after the auditory task. As shown in Figure 2a (individual curves) and $2 \mathrm{~b}$ (summation), the skin temperature curves showed a small but considerable change during odor presentation. However, there was considerable individual variation between trials in an experimental run. Therefore, for each trial, the minute-based mean average temperature was calculated for the different odor presentation periods (Figure 2c).

On the basis of this minute-based temperature profile, we calculated the net change in skin temperature for each experimental run according to the formula described above. This method produced the results shown in Figure 3. In Figure 3, the cases of the participants showing an increase in skin temperature after the task are plotted in the left diagram, while those showing a decrease are represented in the middle diagram. In the right diagram of the Figure, the overall mean values of the net temperature changes between pre- and post-task inhalations for the participants were represented.

Figure 3 shows the skin temperature changes following inhalation of lemon and ylang ylang as a function of the two behavioural tasks. The temperature response to lemon showed opposite signs for the two behavioural tasks: a significant decrease in skin temperature between pre- and post-task inhalations for mental arithmetic (at $p<0.05$ ): $\left|t_{0}\right|=2.585 \geq t_{\mathrm{d} . \mathrm{f}}$. (d.f. $=12, p=0.05)=2.179$ (Figure 3a), and a significant increase for the auditory task (at $p<0.05$ ): $\left|t_{0}\right|=2.655 \geq t_{\text {d.f. }}$ (d.f. $=13, p=0.05)=2.145$ (Figure 3c). For ylang ylang, a decrease was observed after both mental arithmetic (Figure $3 b$ ) and the auditory task (Figure 3d), but this change did not reach statistical significance. 
(a)

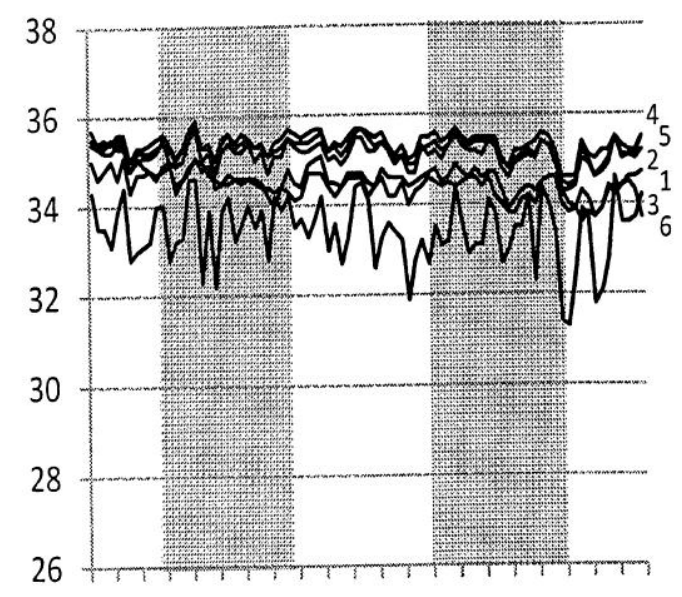

(b)

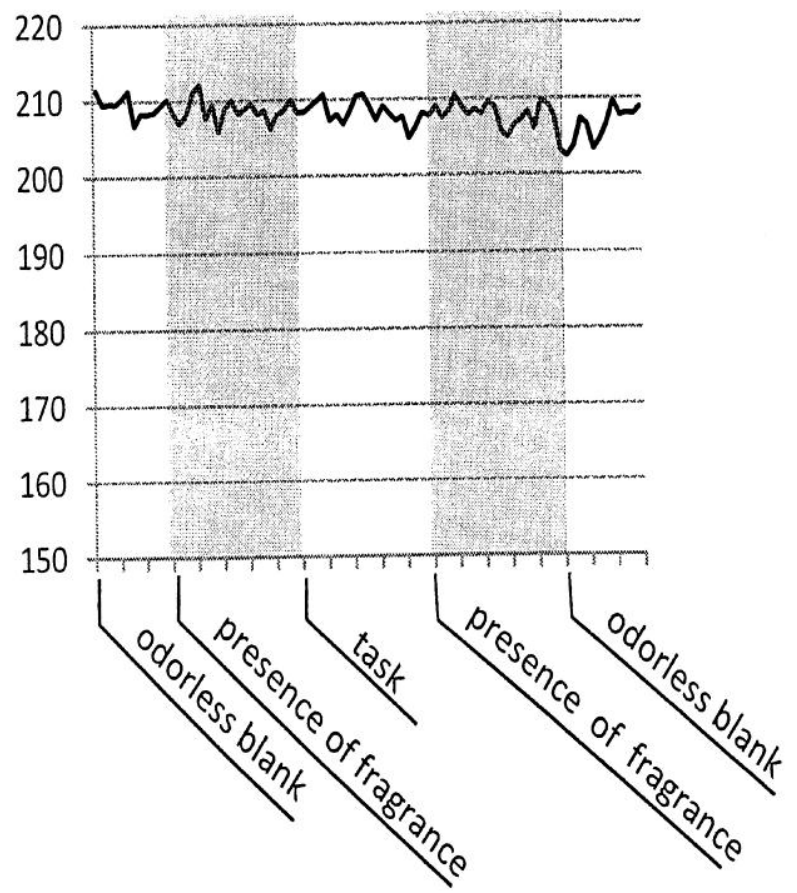

(c)

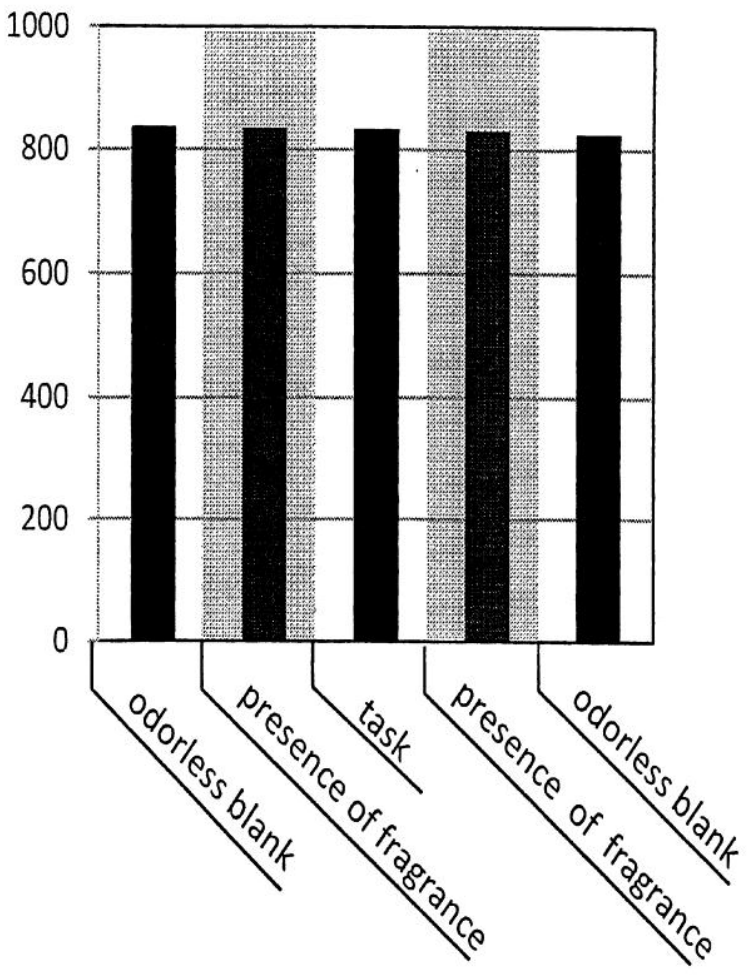

Figure 2. The observed skin temperature changes from a participant following inhalation of lemon in association with the auditory task. (a) Skin temperature records from 6 sensors; (b) the additional skin temperature curve calculated from these data; and (c) a minute-based intensity profile (bar chart) constructed by the integration of the single-temperature curve as shown (b). The numbers assigned to the graph represent the sensor spots on the left hand: 1, the tip of the thumb; 2 , the tip of the first finger; 3 , the tip of the second finger; 4 , the tip of the third finger; 5 , the tip of the fourth finger, and 6 , the palm. 
(a) Lemon/ Mental arithmetic
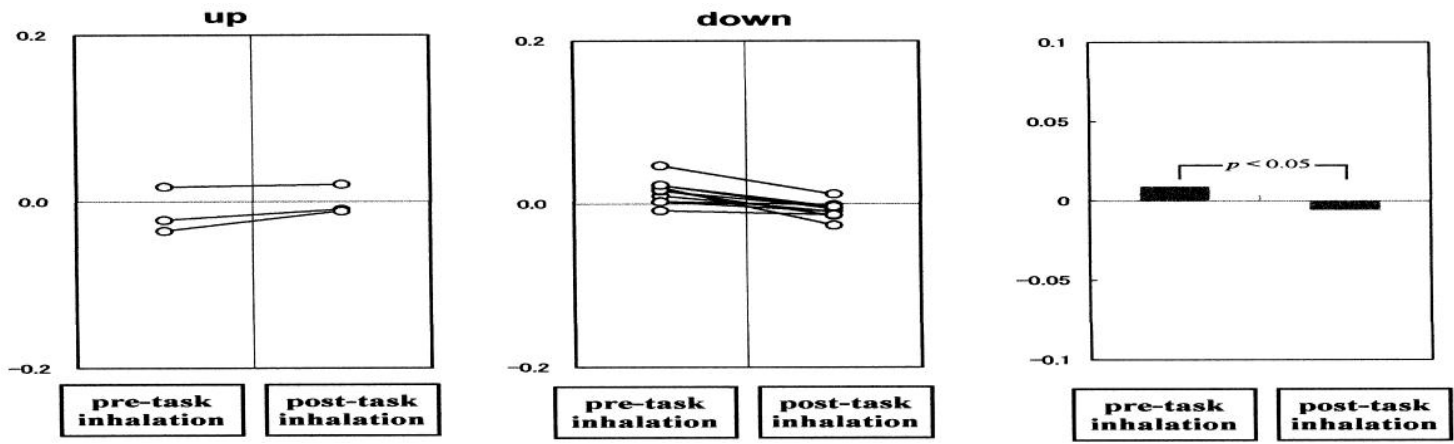

(b) Ylang ylang/ Mental arithmetic
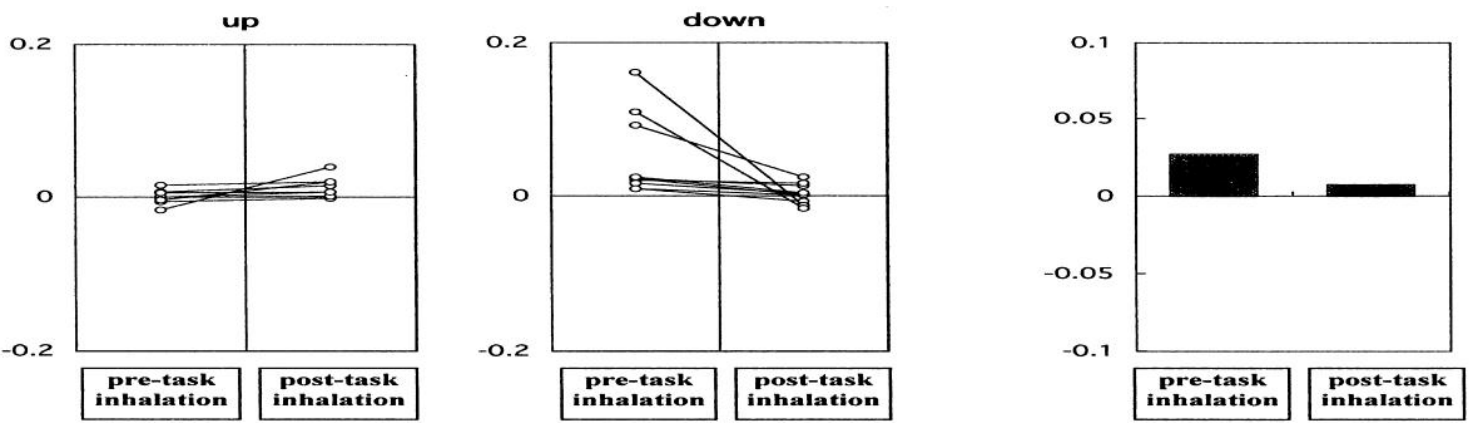

(c) Lemon/ Auditory task
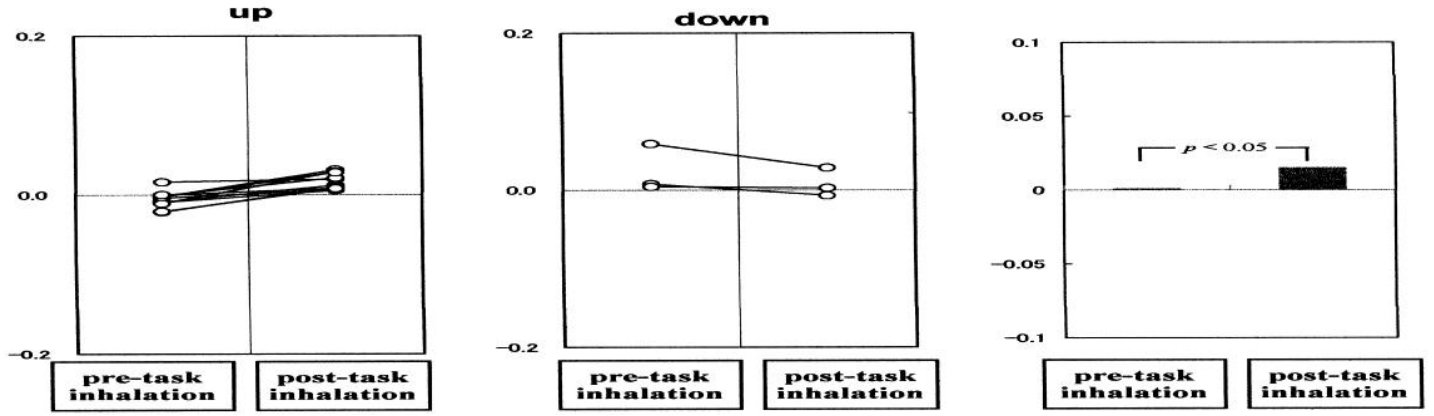

(d) Ylang ylang/ Auditory task
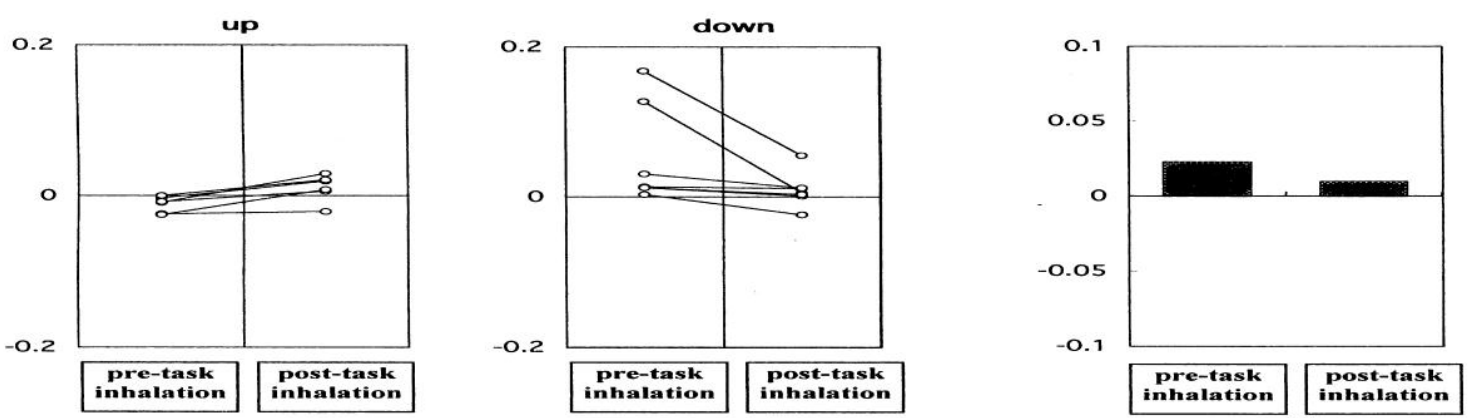

Figure 3. Task dependent skin temperature changes following inhalation of lemon and ylang ylang as a function of behavioral task. 


\section{Results: Verbal (Sensory Evaluation Spectrum) and Non-Verbal (Skin Temperature Changes) Endpoints in the Participants of Inhaling Essential Oil Fragrances as a Function of the Behavioral Task Assigned (Mental Ariyhmetic and Auditory)}

As the skin temperature measurements advanced, we decided to concentrate on just the two behavioral tasks (the mental arithmetic task and the auditory task), and narrowed our focus to contain only the following 12 essential oils (basil, bergamot, cardamom, cinnamon, juniper, lemon, orange, palmarosa, peppermint, sandalwood, spearmint and ylang ylang). Tables 1 and 2 and Figures 4 to 7 summarize the outcomes resulted from the verbal (sensory evaluation spectrum) and non-verbal (skin temperature changes) inquiries on the above-mentioned 12 target odors, respectively.

In Table 1, the total significance scores of the obtained sensory spectra (i.e., the sum of the statistical scores of each descriptor in a given spectrograph: 1.0 for items denoted * (asterisk); 0.5 for items denoted $\pm ; 0.0$ for items that are unmarked) were summarized as a function of behavioral task assigned to the participants. The total significance scores are a convenient index for evaluating whether the relevant spectrographs are statistically significant or not (Sugawara et al., 2008, 2009, 2013, 2015; Yamagata \& Sugawara, 2014). For this purpose, we employed a sign test with $n=13$, corresponding to the number of descriptors used in our sensory test. We found that, for a sign test with $n=13$, the resulting sensory spectra would be significant (at $p<0.05$ ) when the number of descriptors regarded as significant at a probability value of $p<0.05$ according to the $t$-test was greater than 10 (out of 13 descriptors). In contrast, when this value was less than 3 , the null hypothesis could be rejected. Hence, as demonstrated in Table 1 as well as in Figure 1, we found no sensory spectra with total significance scores of $>10$ among the 24 cases listed in Table 1, although 8.5, which was derived from the data for the cinnamon/auditory task (Table 1), was the largest value.

Regardless, the resulting sensory spectra warranted particular interest (Figure 1). Figure 1 shows that there stand three types of sensory spectra. The first "favorable" one was seen in Figure 1d, where the descriptors regarded as significant by a $t$-test had a positive value and were shown above the horizontal axis, this signifies a positive (or favorable) correlation between the fragrance of a given aroma and the type of task, according the positive descriptors (i.e., "fresh," "airy," "elegant," "pleasant," "comfortable," etc.). The next "unfavorable" one was apparent in Figure 1a,b, respectively, in which negative values appeared below the axis, this suggests an unfavorable (negative) correlation between the fragrance and the type of task in terms of the negative descriptors (i.e., "stale," "heavy," "unrefined," "unpleasant," "uncomfortable," etc.). The third "miscellaneous" one was seeable in Figure 1c of which half of the significant descriptors were positive and the other half negative. The sensory attributes of the obtained sensory spectra are of particular relevance, so that these are summarized in Table 1 as a function of behavioral task assigned to the participants.

Meanwhile, for addressing statistical defects associated with the significance of the sensory spectra, we considered a variety of strategies (Sugawara et al., 2013, 2015; Yamagata \& Sugawara, 2014). We conclusively found that multi-channel skin thermometer data might complement the statistical defects of the relevant sensory spectra.

For the data in Figures 4 and 5, the practical potentialities of the skin temperature data for the evaluation of statistical significance might complement any statistical defects associated with the sensory spectrographs, even if the sensory spectra were not statistically significant. Moreover, the subtle differences between the two behavioral tasks could be viewed in terms of verbal (sensory spectrum) and non-verbal (fingertip skin temperature) changes as a function of the two behavioral tasks. In other words, the combination of non-verbal with verbal data might be highly informative, not only for studying the psychophysiological responses of essential oil fragrances, but also for examining the relationship between mood change, odor and its psychophysiological responses in humans.

In this way, the verbal and non-verbal performance associated with the 12 target odors were unified in relation to the two behavioral tasks. The unified 24 odor-task combinations (the 12 target odors in relation to the two tasks) are summarized in Figures 4 to 7.

With respect to skin temperature changes, our finding showed that the essential oils tested so far could be classified into two groups in terms of fingertip skin temperature changes (Table 2): those that elicited an increase (Figure 3c); and those that induced a decrease (Figure 3a,b,d). Given this perspective, we tentatively classified our 12 target odors (i.e., the 24 odor-task combinations) into three categories: (1) the first category included lemon and palmarosa because they elicited opposite changes in skin temperature for the two behavioral tasks (Figure 4); (2) the second category contained basil and juniper, as these were associated with increases in skin temperature for the two behavioral tasks in a non-task dependent fashion (Figure 5); and (3) the other essential oils were temporarily placed in the third category (Figures 6 and 7), since inhalation of these essential oils was associated with decreases in skin temperature for the two tasks in a non-task dependent fashion.

In regard to the essential oils belonging to the third category in our criteria (bergamot, cardamom, cinnamon, orange, peppermint, sandalwood, spearmint, and ylang ylang), a more detailed inspection (mention later) of the obtained 
sensory spectrographs led us to classify these further into two groups: those associated with contrasting sensory spectra in a task-dependent fashion (i.e., one produced an increase and the other produced a decrease) (Figure 6); and those (the rest) associated with undistinguished sensory spectra (Figure 7). Essential oils of bergamot, peppermint, sandalwood, and ylang ylang appeared to be constituents of the former (Figure 6), whereas cardamom, cinnamon, orange, and spearmint constituted the latter (Figure 7).

Note that the temperature response to inhalation of palmarosa occurred in opposite directions for the two behavioral tasks, similar to lemon: we observed a significant increase in skin temperature between pre- and post-task inhalations for mental arithmetic (at $p<0.01)$ : $\left|t_{0}\right|=3.555 \geq t_{\text {d.f. }}($ d.f. $=10, p=0.01)=3.106$, and a tendency for skin temperature to decrease for the auditory task, although this change did not reach statistical significance. Additionally, a significant increase in skin temperature was seen for basil/mental arithmetic (at $p<0.05)$ : $\left|t_{0}\right|=2.173 \geq t_{\text {d.f. }}($ d.f. $=16, p=0.05)=$ 2.110, and juniper/mental arithmetic (at $p<0.01)$ : $\left|t_{0}\right|=3.587 \geq t_{\text {d.f. }}($ d.f. $=11, p=0.01)=3.055$. We also observed a significant decrease in skin temperature between pre- and post-task inhalations for sandalwood and spearmint, as for sandalwood/auditory task (at $p<0.05):\left|t_{0}\right|=2.318 \geq t_{\text {d.f. }}($ d.f. $=19, p=0.05)=2.086$, and as to spearmint $/ \mathrm{mental}$ arithmetic (at $p<0.01):\left|t_{0}\right|=4.153 \geq t_{\text {d.f. }}($ d.f. $=16, p=0.01)=2.898$.

Table 1. Summary of verbal (semantic) study for the perceived odor quality for a given aroma as a function of behavioral task (mental arithmetic and the auditory) assigned to the participants. Three types of sensory spectra (see Figure 1) were observed: 1) those showing a "favorable" correlations between the fragrances and the task; 2) those accompanying an "unfavorable" correlations; and 3) those that were recognized as "miscellaneous". Table contains the sensory attributes and the concerned total significance scores (see text) resulting from a statistical analysis for each spectrograph.

\begin{tabular}{|c|c|c|}
\hline \multicolumn{3}{|c|}{$\begin{array}{l}\text { The sensory attribute and total significance score of sensory spectrograph for a } \\
\text { given aroma in relation to the task assigned to the participants with the number } \\
\text { of participants in parenthesis. }\end{array}$} \\
\hline \multirow[b]{2}{*}{ essential oils } & \multicolumn{2}{|c|}{ Task assigned to the participants } \\
\hline & $\begin{array}{c}\text { mental } \\
\text { arithmetic }\end{array}$ & $\begin{array}{c}\text { auditory } \\
\text { task }\end{array}$ \\
\hline \multirow[t]{2}{*}{ basil } & "favorable"/ & "favorable"/ \\
\hline & $5.0(n=22)$ & $0.0(n=22)$ \\
\hline \multirow[t]{2}{*}{ bergamot } & "unfavorable"/ & "favorable"/ \\
\hline & $2.0(n=24)$ & $2.5(n=18)$ \\
\hline \multirow[t]{2}{*}{ cardamon } & "miscellaneous"/ & "unfavorable"/ \\
\hline & $0.0(n=24)$ & $0.0(n=23)$ \\
\hline \multirow[t]{2}{*}{ cinnamon } & "miscellaneous"/ & "favorable"/ \\
\hline & $2.0(n=36)$ & $8.5(n=41)$ \\
\hline \multirow[t]{2}{*}{ juniper } & "favorable"/ & "favorable"/ \\
\hline & $6.5(n=17)$ & $6.5(n=19)$ \\
\hline \multirow[t]{2}{*}{ lemon } & "unfavorable"/ & "miscellaneous"/ \\
\hline & $8.0(n=43)$ & $7.0(n=41)$ \\
\hline \multirow[t]{2}{*}{ orange } & "miscellaneous"/ & "miscellaneous"/ \\
\hline & $5.0(n=22)$ & $1.0(n=30)$ \\
\hline \multirow[t]{2}{*}{ palmarosa } & “unfavorable"/ & "favorable"/ \\
\hline & $2.0(n=18)$ & $3.5(n=21)$ \\
\hline \multirow[t]{2}{*}{ peppermint } & "unfavorable"/ & "favorable"/ \\
\hline & $6.0(n=20)$ & $3.5(n=23)$ \\
\hline \multirow[t]{2}{*}{ sandalwood } & "unfavorable"/ & "favorable"/ \\
\hline & $2.0(n=21)$ & $6.5(n=22)$ \\
\hline \multirow[t]{2}{*}{ spearmint } & "miscellaneous"/ & "favorable"/ \\
\hline & $4.5(n=18)$ & $3.0(n=18)$ \\
\hline \multirow[t]{2}{*}{ ylang ylang } & "unfavorable"/ & "favorable"/ \\
\hline & $2.0(n=19)$ & $5.5(n=24)$ \\
\hline
\end{tabular}


Table 2. Summary of the skin temperature changes resulting from non-verbal study for a given aroma as a function of behavioral task (mental arithmetic and the auditory). We calculated the net intensity change in skin temperature between pre- and post-task inhalations with respect to the odorless blank and the target fragrance (see text) in each trial. The obtained 24 odor-task combinations could be divided into two groups: those that elicited an increase; and those that led to a decrease.

\begin{tabular}{|c|c|c|}
\hline \multirow[b]{2}{*}{ essential oils } & \multicolumn{2}{|c|}{ Task assigned to the participants } \\
\hline & $\begin{array}{c}\text { mental } \\
\text { arithmetic }\end{array}$ & $\begin{array}{l}\text { auditory } \\
\text { task }\end{array}$ \\
\hline basil & $\begin{array}{c}\text { an increase (at } p<0.05) \\
(n=17)\end{array}$ & $\begin{array}{l}\text { a slight increase } \\
\qquad(n=19)\end{array}$ \\
\hline bergamot & a decrease $(n=14)$ & $\begin{array}{l}\text { a slight decrease } \\
\qquad(n=12)\end{array}$ \\
\hline cardamon & a decrease $(n=18)$ & a decrease $(n=20)$ \\
\hline cinnamon & a decrease $(n=18)$ & $\begin{array}{l}\text { a slight decrease } \\
\qquad(n=18)\end{array}$ \\
\hline juniper & $\begin{array}{c}\text { an increase (at } p<0.01) \\
(n=12)\end{array}$ & an increase $(n=20)$ \\
\hline lemon & $\begin{array}{c}\text { a decrease }(\text { at } p<0.05) \\
(n=13)\end{array}$ & $\begin{array}{c}\text { an increase (at } p<0.05) \\
(n=14)\end{array}$ \\
\hline orange & a decrease $(n=20)$ & a decrease $(n=20)$ \\
\hline palmarosa & $\begin{array}{c}\text { an increase (at } p<0.01) \\
(n=11)\end{array}$ & a decrease $(n=18)$ \\
\hline peppermint & a decrease $(n=18)$ & a decrease $(n=20)$ \\
\hline sandalwood & a decrease $(n=20)$ & $\begin{array}{c}\text { a decrease (at } p<0.05) \\
(n=20)\end{array}$ \\
\hline spearmint & $\begin{array}{c}\text { a decrease }(\text { at } p<0.01) \\
(n=17)\end{array}$ & a decrease $(n=18)$ \\
\hline ylang ylang & a decrease $(n=18)$ & a decrease $(n=20)$ \\
\hline
\end{tabular}




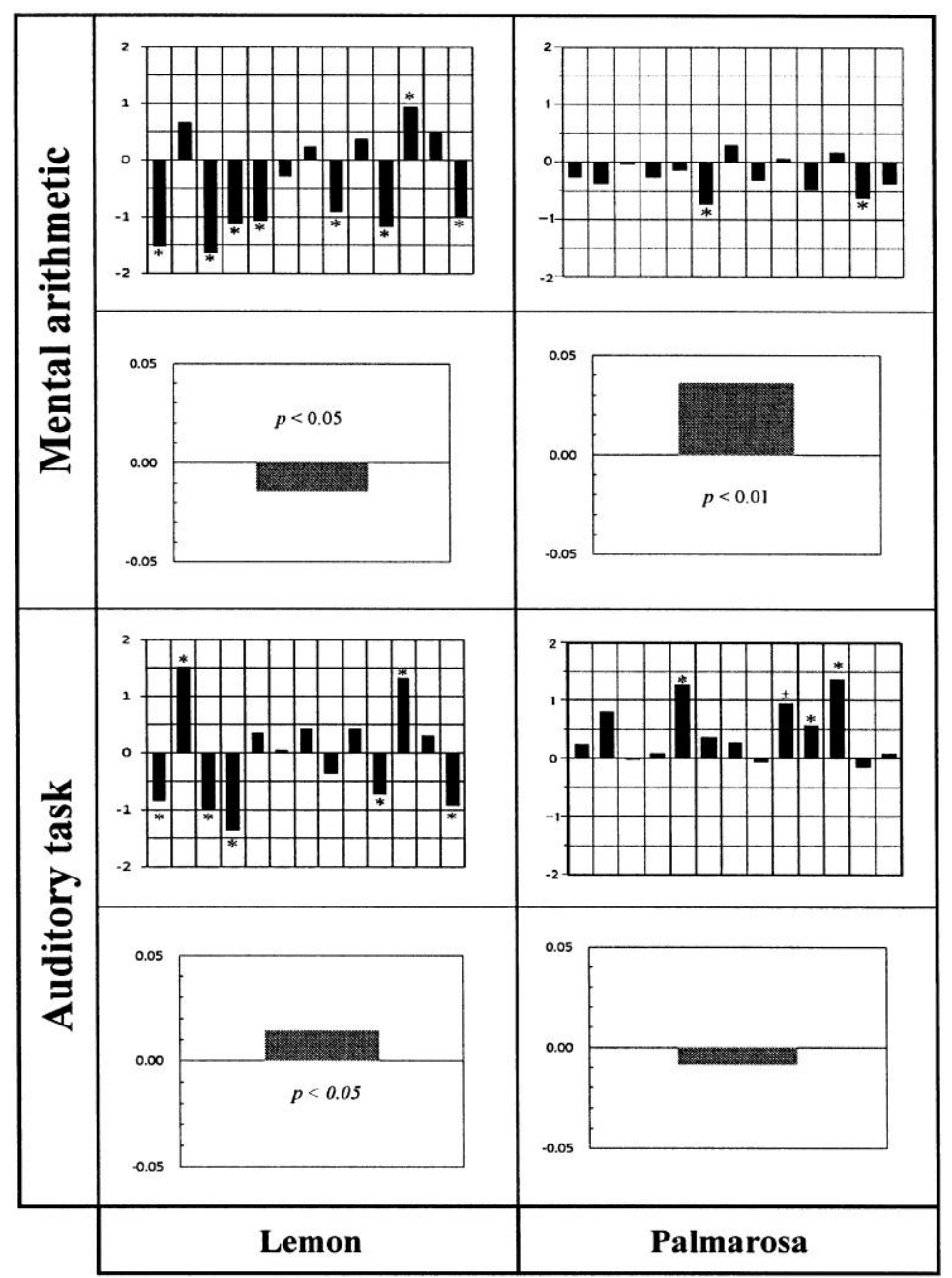

Figure 4. Summary of the verbal and non-verbal responses following inhalation of essential oils of lemon and palmarosa in terms of the sensory evaluation spectra and skin temperature changes as a function of behavioral task. See Tables 1 and 2 for more information about the participants in the sensory profiling study and the skin temperature study, respectively. 


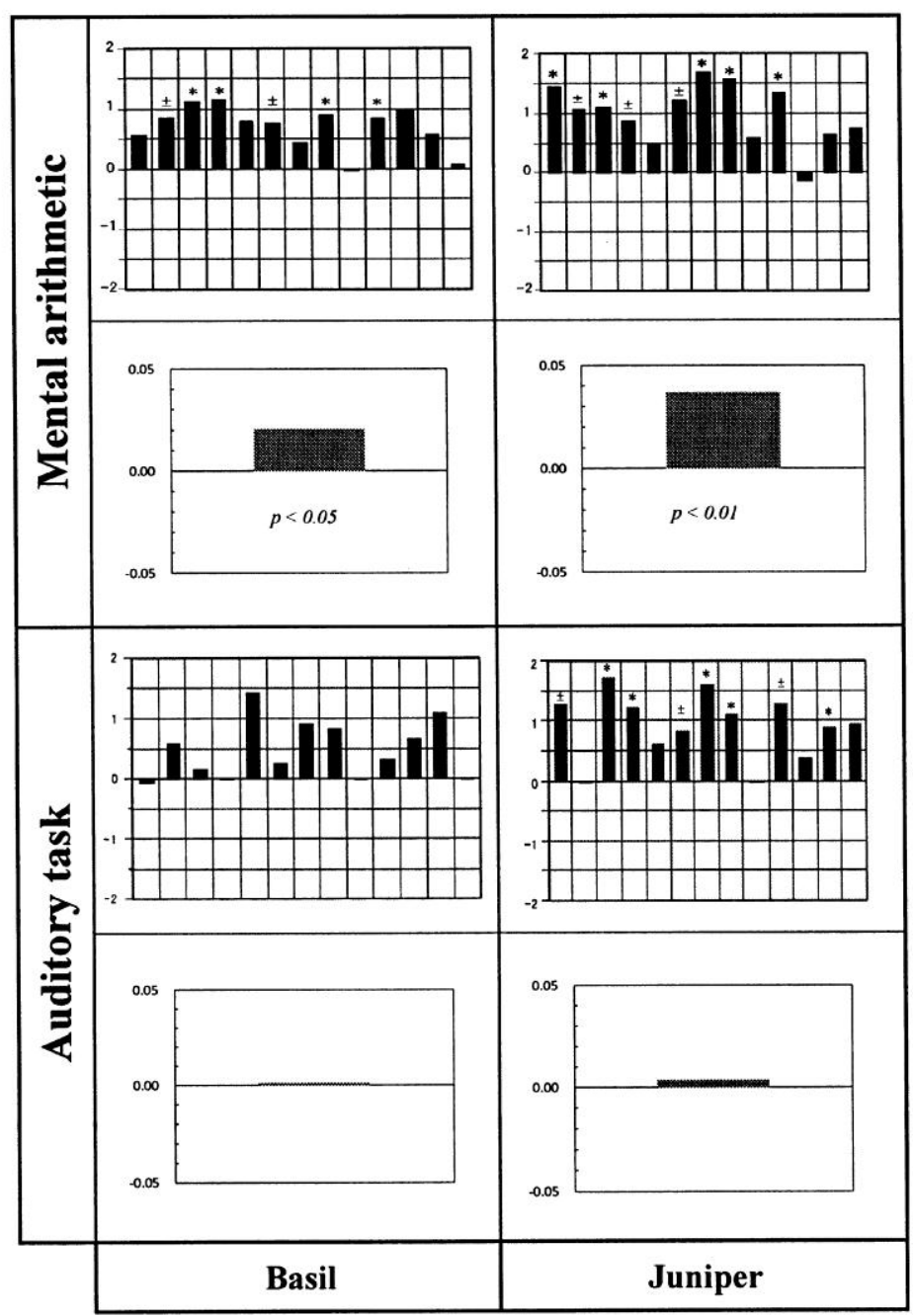

Figure 5. Summary of the verbal and non-verbal responses following inhalation of essential oils of basil and juniper in terms of the sensory evaluation spectra and skin temperature changes as a function of behavioral task. The circumstances are identical to those shown in Figure 4. 


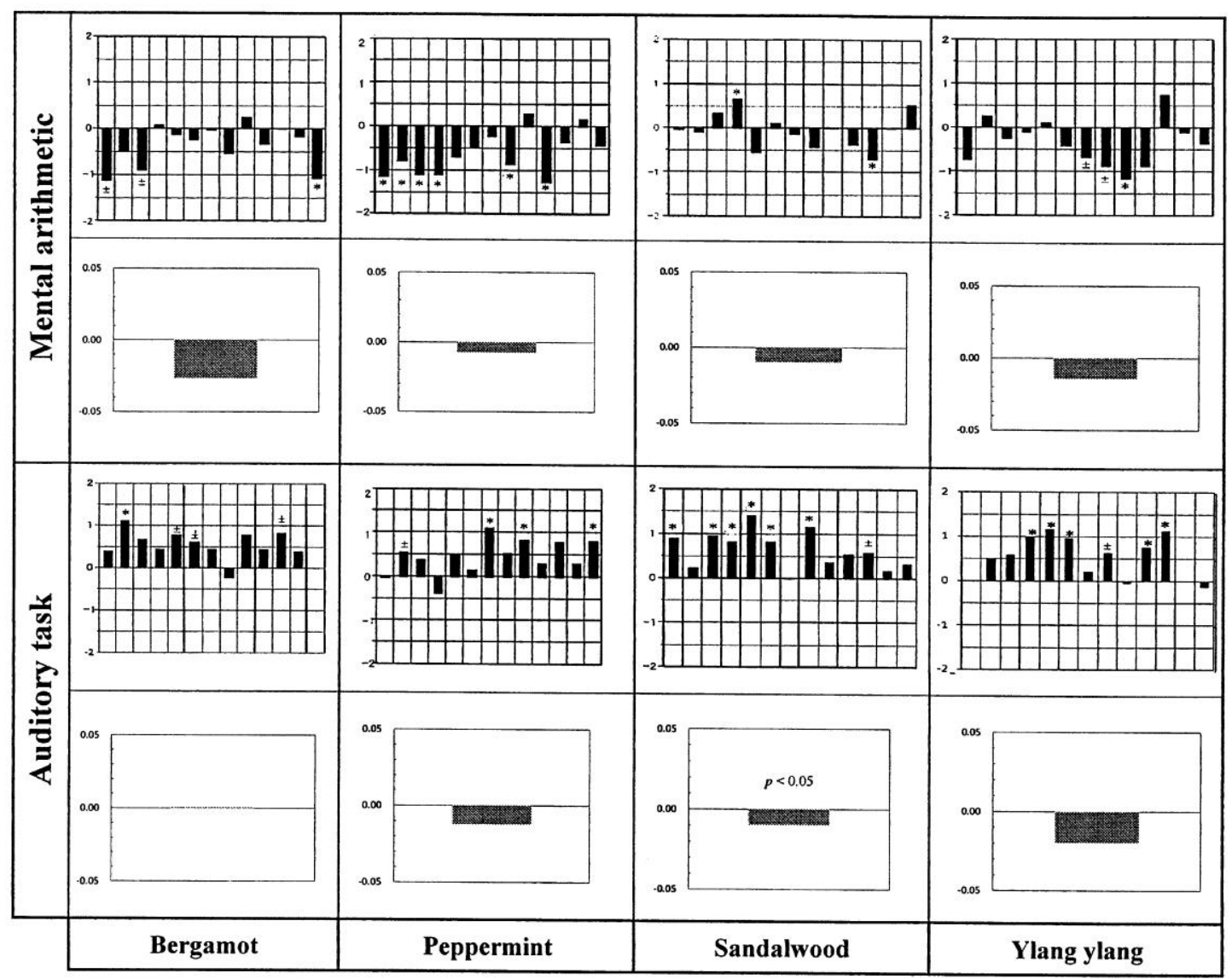

Figure 6. Summary of the verbal and non-verbal responses following inhalation of essential oils of bergamot, peppermint, sandalwood, and ylang ylang in terms of the sensory evaluation spectra and skin temperature changes as a function of behavioral task. We made reconstruction of the architecture, employing the concept of "harmonization" introduced by Hongratanaworakit and Buchbauer to describe the effect of ylang ylang (2004). When we used the obtained sensory spectra and skin temperature profiles of ylang ylang as a reference to evaluate the other tested odorants, we found that bergamot, peppermint and sandalwood could be classified as essential oils materializing "harmonization". The circumstances are identical to those shown in Figure 4. 


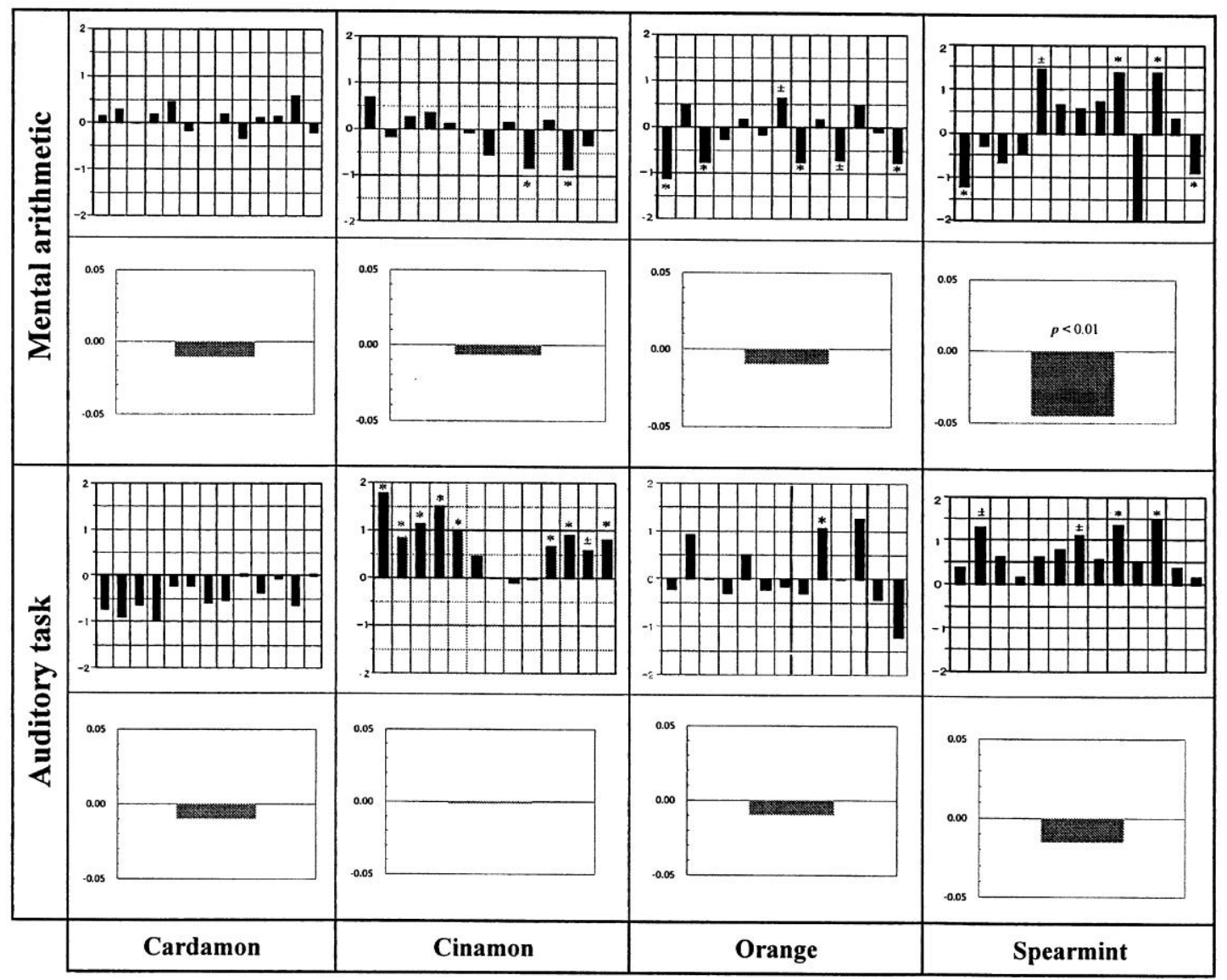

Figure 7. Summary of the verbal and non-verbal responses following inhalation of essential oils of cardamom, cinnamon, orange, and spearmint in terms of the sensory evaluation spectra and skin temperature changes as a function of behavioral task. The circumstances are identical to those shown in Figure 4.

\section{Discussion}

Emotional excitement or apprehension is known to induce a slight increase in human skin temperature (Elam \& Wallin, 1987; Oka et al., 2001, 2008; Yamakoshi et al., 2007; Ziegler \& Cash, 1938). Although several authors have demonstrated stress-induced skin temperature changes, the mechanisms by which odorants induce such changes are unknown. As blood vessels are supplied only by vasoconstrictor efferents, it has been suggested that emotional stress leads to cutaneous vasoconstriction, thus lowering skin temperature (Abramson \& Ferris 1940; Arnott \& Macfie 1948; Gaskell 1956; Kellerova \& Delius 1969; Roddie et al. 1957; Vallbo et al. 1979). Sympathetic nerve-mediated vasodilation has also been reported to occur during stress (Allwood et al., 1959; Harris et al., 1952; Roddie 1983), although there are no known vasodilator nerve fibers connected to the cutaneous vessels in humans (Rowell, 1981). Elam and Wallin (1987) observed that mental stress caused vasoconstriction in warm participants and vasodilation in cold participants. Accordingly, they suggested that a thermoregulatory mechanism might exert a powerful modulatory effect on different cutaneous vasomotor reactions (Elam \& Wallin, 1987; Oberle et al., 1988). In addition, there are short channels in the fingers, palms, and earlobes of humans that connect arterioles to venules, bypassing the capillaries. These arteriovenous anastomoses or shunts have thick muscular walls and are abundantly innervated, presumably by vasoconstrictor nerve fibers. Skin temperature also depends on the state of the capillaries and venules; in cold skin the arterioles are constricted and the capillaries are dilated, while in warm skin both are dilated. Sweat production is another important factor, because it affects skin temperature, not only due to the vaporization of water, but also due to emotional effects via sudomotor nerve fibers (Libert et al., 1978; Nadel et al., 1971; Sugenoya et al., 1995; Wurster \& McCook, 1969).

Despite the complexity of the factors that influence cutaneous vascular responses with respect to skin temperature changes, our findings showed that the essential oils tested in the present study could be classified into two groups in terms of fingertip skin temperature changes (Table 2): those that elicited an increase; and those that induced a decrease. If feelings of excitement or apprehension induce slight increases in skin temperature (Elam \& Wallin, 1987; Oka et al., 2001, 2008; Yamakoshi et al., 2007; Ziegler \& Cash, 1938), it is reasonable to assume that essential oils can be regarded as having either distressing/agitating properties when associated with increases in skin temperature or relaxing/sedating 
properties when associated with decreases in skin temperature.

Mehrabian and Russell (1974) constructed a set of verbal texts describing different situations, and a scale for rating these texts (the Semantic Differential Scale). They asserted that pleasure and arousal are the principal dimensions of affective response to the environment. Here, pleasure can be defined as the degree to which one has favorable feelings towards a situation, while arousal is defined as the degree to which one feels excited in the situation. When this method was applied to materials describing common events, Bensafi, et al. (2002) demonstrated that the first two factors accounting for most of the variance in descriptions were pleasure and arousal. Perception of emotional stimuli is thus associated with explicit reactions, such as verbal responses, and to implicit output, such as variations in the autonomic nervous system (Greenwald et al., 1989; Lang et al., 1998).

Based on Bensafi, et al. (2002) we speculated that: (1) the sensory spectra can be used as an index of pleasantness (or unpleasantness); and (2) the overall mean values of the net skin temperature changes between pre- and post-task inhalations can be regarded as an index of arousal state. Specifically, upward sensory spectra can be considered to represent favorable (pleasant) feelings towards a situation while participants inhale the fragrance of a given aroma, whereas downward sensory spectra can represent unfavorable (unpleasant) feelings towards a situation. Likewise, an increase in skin temperature (i.e., the overall mean values of the net skin temperature changes between pre- and post-task inhalations) could designate a distressed/agitated state of the participant as well as distressing/agitating properties of a given aroma, while a decrease could denote a relaxed/sedated state and relaxing/sedating properties of a target odor.

If we accept the above-mentioned presumptive requirements, then basil and juniper, which were members of the second category in our criteria (Figure 5), could be regarded as possessing both favorable/pleasant properties and distressing/agitating properties because they were associated with a non-task-dependent upward sensory spectra as well as non-task dependent increases in skin temperature.

In this context, however, group membership of bergamot, cardamom, cinnamon, orange, peppermint, sandalwood, spearmint, and ylang ylang would be confusing. This is why we first attempted to classify the essential oils into two groups: those (bergamot, peppermint, sandalwood, and ylang ylang) associated with contrasting sensory spectra in a task-dependent fashion (one was upward and the other was downward); and the remainder (cardamom, cinnamon, orange, and spearmint) that were associated with contrasting sensory spectra in a non-task-dependent fashion.

We will address the former group of essential oils first, i.e., those comprising exactly half of the essential oils mentioned above. This is because Hongratanaworakit and Buchbauer made an intriguing observation during two studies of ylang ylang in 2004 and 2006. Hence, we will hereinafter deal with ylang ylang as a typical example of this group, for which a characteristic feature could be an obtained sensory spectra that clashes with the results of behavioral tasks in terms of direction: the sensory spectrograph was upward when the participants completed the mental arithmetic task and downward when they completed the auditory task. Note that the decreases in skin temperature associated with the two tasks were identical to those found for the remaining essential oils (cardamom, cinnamon, orange, and spearmint).

In Hongratanaworakit and Buchbauer's first study (2004), the authors characterized the effect of ylang ylang after inhalation as harmonizing rather than relaxing/sedating on the basis of their findings that administration of ylang ylang after inhalation led to a decrease in blood pressure and pulse rate. However, they observed increased participative attention and alertness in response to administration of ylang ylang. Thus, they generated the concept of "harmonization," which is consistent with otherwise contradictory psychophysiological outcomes. In their subsequent report (Hongratanaworakit \& Buchbauer, 2006), the authors reported that transdermal absorption of ylang ylang caused a decrease in blood pressure and an increase in participative calmness and relaxation compared with a control scenario, and suggested that administration of ylang ylang via transdermal absorption has a relaxing/sedating effect under specific experimental conditions.

Given their findings, our ylang ylang data is intriguing. The inhalation of ylang ylang in combination with mental arithmetic produced an unpleasant/unfavorable feeling after inhalation, whereas inhalation combined with the auditory task brought about a pleasant (favorable) feeling. Conversely, ylang ylang seemed to have similar relaxing/sedating properties during both the mental arithmetic and the auditory tasks. It seems that the observed effect of ylang ylang in our experiment, in combination with mental arithmetic, was in good agreement with the Hongratanaworakit and Buchbauer's conception of "harmonization" (2004). Given this notion, we searched for other essential oils that had the same profile as ylang ylang in terms of task-dependent sensory spectra and fingertip skin temperature changes. The results are shown in Figure 6. We identified three other essential oils that shared the sensory spectra of ylang ylang in terms of net intensity fingertip skin temperature changes. These were bergamot, peppermint, and sandalwood.

Thus, we reconsidered the remaining half of the essential oils (cardamom, cinnamon, orange, and spearmint). In this group, they all were associated with decreases in skin temperature during the two behavioral tasks, but we found no 
common features in their sensory spectra. The total significance scores for these essential oils were mostly less than 3 , so we expected that a null hypothesis could be rejected. A small exception was seen for a cinnamon/auditory task (a total significance score of 8.5) and a spearmint/mental arithmetic (a total significance score of 4.5). Additionally, in the sensory spectrograph for spearmint/mental arithmetic, half of the significant descriptors were positive and the other half negative. Altogether, the essential oils belonging to this group (cardamom, cinnamon, orange, and spearmint) could be regarded as having relaxing/sedating properties, as shown in Figure 7.

Along this line of thinking, we classified lemon and palmarosa as having miscellaneous effects, while these were assigned to the first category in our criteria (Figure 4). Because inhalation of these fragrances produced skin temperature changes in opposite directions for the two behavioral tasks: for lemon, we observed a significant decrease in skin temperature between pre- and post-task inhalations (at $p<0.05$ ) during mental arithmetic, and a significant increase (at $p<0.05$ ) during the auditory task. For palmarosa, we observed a significant increase (at $p<0.01$ ) in skin temperature during mental arithmetic, and a decreasing tendency in skin temperature during the auditory task (although this change did not reach statistical significance). Based on the above findings, that a significant increase in skin temperature was elicited by lemon/the auditory task (at $p<0.05)$ and palmarosa/mental arithmetic (at $p<0.01)$ could indicate that these essential oils have distressing/agitating properties. However, a significant decrease in skin temperature induced by lemon/ mental arithmetic (at $p<0.05$ ) and palmarosa/the auditory task could be regarded as a reflection of their relaxation/sedation properties.

A sequence of our research findings suggested that versatile psychophysiological potencies were determined by the nature of the tested odors. As stated by Lorig and Schwartz (1988), odors act as neurophysiological stimuli by causing different perceptions, which, in turn, lead to diverse odor reactions, depending on the internal and extraneous conditions of the participants. Thus, odors can have versatile and inherent psychophysiological effects. In the present study, we observed evidence of the intrinsic and versatile psychophysiological effects of odors, which were a function of different behavioral tasks assigned to participants.

Lastly, controversial findings are often reported in aroma research. It is of particular importance to mention the controversy surrounding the lemon fragrance. Support for the hypothesis that the lemon fragrance causes distress/agitation has been provided by the observation that lemon aroma causes an increase in heart rate (Kikuchi et al., 1992; Yamaguchi, 1990). However, the opposite is supported by the findings of a study by Manley (1993), in which the administration of a lemon aroma through an air conditioning system resulted in a decrease in contingent negative variation $(\mathrm{CNV})$ as well as a decrease in key entry errors of video display terminal (VDT) operators. In a recent study (Akipinar, 2005) in which the author was interested in identifying the effects of lemon on cognitive learning, attention, and memory, a lemon aroma increased the attention levels of students (at $p<0.05$ ), enhanced memory (at $p<0.05$ ), and had positive effects on cognitive learning (at $p<0.05$ ).

Similar controversies exist for other aromas. For instance, Manley (1993) reported that a ylang ylang aroma appeared to possess a stimulating effect, as it caused an increase in CNV magnitude. Hongratanaworakit and Buchbauer (2004, 2006) demonstrated that its effect can be characterized as relaxation/sedation. With respect to sandalwood, Hongratanaworakit, Heuberger, and Buchbauer compared the effects of sandalwood administered via transdermal absorption (Hongratanaworakit, et al., 2004) and inhalation (Heuberger et al., 2006) on physiological parameters, as well as mental and emotional conditions, in healthy human participants. The authors concluded that the administration of sandalwood oil via transdermal absorption and in specific experimental conditions provoked physiological deactivation and behavioral activation (Hongratanaworakit, et al., 2004), while administration via inhalation and in different experimental circumstances elevated pulse rate, skin conductance level, and systolic blood pressure (Heuberger et al., 2006). As for peppermint, evidence for its stimulating properties includes an observation that peppermint aroma caused an increase in electroencephalography (EEG) speed and heart rate during sleep (Badia et al., 1990), an increase in CNV magnitude (Manley, 1993; Torii et al., 1998), a decrease in theta activity (Klemm et al., 1992), and enhanced EEG and behavioral arousal during stage 1 sleep (Carskadon \& Herz, 2004). However, arguments against the stimulating properties of peppermint include the finding that peppermint aroma produced a significant decrease in gross speed, net speed, and accuracy in a typing task (Barker et al., 2003); more NREM sleep, less REM sleep, and more slow-wave sleep (Goel \& Lao, 2006); and increased alertness, decreased temporal demand, and decreased frustration during simulated driving (Raudenbush et al., 2009).

In consideration of the above-mentioned opposing views about the psychophysiological properties of essential oils, and given our findings which suggested that the tested odors in this research manifested innate versatile psychophysiological potencies of essential oil fragrances, the described controversies may in part be a reflection of the versatile psychophysiological properties of essential oils. The unique features related to early levels of the olfactory system have been extensively studied and documented (Axel, 1995; Buck, 1996; Buck \& Axel, 1991; Li et al., 2008; Lledo et al., 2005; Mombaerts, 1999; Yoshida \& Mori, 2007; Zhang \& Firestein, 2002), however, little is known about 
processes operating upstream. In each experimental run in this research, the fragrant compound given to the participants was the same. Thus a similar set of odorant receptors were activated in each participant at the entrance to the olfactory system. Therefore the subtle nuances of expression of odor discrimination and responses in our findings can be considered to result from diversity upstream of this point in the process of olfaction. Further research is needed to characterize the mechanisms underlying odor discrimination beyond the early stages of olfactory processing. The limbic system is likely to be involved, as it includes the amygdala, septum, hippocampus, anterior thalamus, and hypothalamus. It plays a vital role in motivation, memory, emotions, and instinctive behaviors (Buckle, 2004; Price \& Price, 2007). Thus, it is possible that the elucidation of higher-order olfactory processing, as well as an improved understanding of the versatile psychophysiological properties of essential oils, especially those associated with task-dependence, may contribute to the resolution of several controversies often seen in aroma research.

\section{Acknowledgements}

This work was partly supported by grants-in-aid for Scientific Research ([10680122] to Y.S. and [13680124] to Y.S.) from the Ministry of Education, Culture and Science of Japan.

\section{References}

Abramson, D. L., \& Ferris, E. B. (1940). Responses of Blood-Vessels in the Resting Hand and Forearm to Various Stimuli. American Heart Journal, 19, 541-553. http://dx.doi.org/10.1016/S0002-8703(40)90195-8

Akipinar, B. (2005). The Role of Sense of Smell in Learning and the Effects of Aroma in Cognitive Learning. Pakistan Journal of Social Sciences, 3, 952-960.

Allwood, M. J., Barcroft, H., Hayes, J. P. L. A., \& Hirsjarvi, E. A. (1959). The Effect of Mental Arithmetic on the Blood Flow through Normal, Sympathectomized and Hyperhidrotic Hands. The Journal of Physiology, 148, 108-116. http://dx.doi.org/10.1113/jphysiol.1959.sp006276

Arnott, W. M., \& Macfie, J. M. (1948). Effect of Ulnar Nerve Block on Blood Flow in the Reflexly Vasodilated Digit. The Journal of Physiology, 107, 233-238.

Axel, R. (1995). The Molecular Logic of Smell. Scientific American, 273, $130-137$. http://dx.doi.org/10.1038/scientificamerican1095-154

Badia, P., Wesensten, N., Lammers, W., Culpepper, J., \& Harsh, J. (1990). Responsiveness to Olfactory Stimuli Presented in Sleep. Physiology Behavior, 48, 87-90.

Barker, S., Grayhem, R, Koon, J., Perkins, J., Whalen, A., \& Raudenbush, B. (2003). Improved Performance on Clerical Tasks Associated with Administration of Peppermint Odor. Perceptual Motor Skills, 97, 1007-1010. http://dx.doi.org/10.2466/pms.2003.97.3.1007

Bensafi, M., Rouby, C., Farget, V., Bertrans, B., Vigouroux, M., \& Holley, A. (2002). Autonomic Nervous System Responses to Odours: The Role of Pleasantness and Arousal. Chemical Senses, 27, 703-709. http://dx.doi.org/10.1093/chemse/27.8.703

Billot, M., \& Wells, F. (1975). Perfumery Technology: Art, Science, Industry. New York: John Wiley.

Buchbauer, G., \& Jirovetz, L. (1994). Aromatherapy-Use of Fragrances and Essential Oils as Medicaments. Flavour and Fragrance Journal, 9, 217-222. http://dx.doi.org/10.1002/ffj.2730090503

Buck, L. (1996). Information Coding in the Vertebrate Olfactory System. Annual Review of Neuroscience, 19, $517-544$. http://dx.doi.org/10.1146/annurev.ne.19.030196.002505

Buck, L., \& Axel, R. (1991). A Novel Multigene Family May Encode Odorant Receptors: A Molecular Basis for Odor Recognition. Cell, 65, 175-187. http://dx.doi.org/10.1016/0092-8674(91)90418-X

Buckle, J. (1999). Use of Aromatherapy as a Complementary Treatment for Chronic Pain. Alternative Therapies in Health and Medicine, 5, 42-51.

Buckle, J. (2004). Clinical Aromatherapy: Essential Oils in Practice (2nd ed.). New York: Elsevier.

Carskadon, M. A., \& Herz, R. S. (2004). Minimal Olfactory Perception during Sleep: Why Odor Alarms Will Not Work for Humans. Sleep, 27, 402-405.

Edge, J. (2003). A Pilot Study Addressing the Effect of Aromatherapy Massage on Mood, Anxiety and Relaxation in Adult Mental Health. Complementary Therapies in Nursing and Midwifery, 9, 90-97. http://dx.doi.org/10.1016/S1353-6117(02)00104-X

Elam, M., \& Wallin, B. G. (1987). Skin Blood Flow Responses to Mental Stress in Man Depend on Body Temperature. Acta Physiologica Scandinavica, 129, 429-431. http://dx.doi.org/10.1111/j.1365-201X.1987.tb10609.x 
Gaskell, P. (1956). Are There Sympathetic Vasodilator Nerves to the Vessels of the Hand? The Journal of Physiology, 131, 647-656. http://dx.doi.org/10.1113/jphysiol.1956.sp005489

Goel, N., \& Lao, R. P. (2006). Sleep Changes Vary Odor Perception in Young Adults. Biological Psychology, 71, 341-349. http://dx.doi.org/10.1016/j.biopsycho.2005.07.004

Greenwald, M. K., Cook, E. W., \& Lang, P. J. (1989). Affective Judgment and Psychophysiological Response: Dimensional Covariation in the Evaluation of Pictorial Stimuli. Journal of Psychophysiology, 3, 51-64.

Harris, R., Martin, A. J., \& Williams, H. S. (1952). Correlation of Skin Temperature and Circulatory Changes in Muscle and Subcutaneous Tissues of the Hand during Trunk Heating. Clinical Science, 11, 429-440.

Heuberger, E., Hongratanaworakit, T., \& Buchbauer, G. (2006). East Indian Sandalwood and $\alpha$-Santalol Odor Increase Physiological and Self-Rated Arousal in Humans. Planta Medica, 72, 792-800. http://dx.doi.org/10.1055/s-2006-941544

Holmes, C., Hopkins, V., Hensford, C., MacLaughlin, V., Wilkinson, D., \& Rosenvinge, H. (2002). Lavender Oil as a Treatment for Agitated Behaviour in Severe Dementia: A Placebo Controlled Study. International Journal of Geriatric Psychiatry, 17, 305-308. http://dx.doi.org/10.1002/gps.593

Hongratanaworakit, T., \& Buchbauer, G. (2004). Evaluation of the Harmonizing Effect of Ylang-Ylang Oil on Humans after Inhalation. Planta Medica, 70, 632-636. http://dx.doi.org/10.1055/s-2004-827186

Hongratanaworakit, T., \& Buchbauer, G. (2006). Relaxing Effect of Ylangylang Oil on Humans after Transdermal Absorption. Phytotherapy Research, 20, 758-763. http://dx.doi.org/10.1002/ptr.1950

Hongratanaworakit, T., Heuberger, E., \& Buchbauer, G. (2004). Evaluation of the Effects of East Indian Sandalwood Oil and $\alpha$-Santalol on Humans after Transdermal Absorption. Planta Medica, 70, 3-7. http://dx.doi.org/10.1055/s-2004-815446

Jimbo, D., Kimura, Y., Taniguchi, M., Inoue, M., Urakami, K. (2009). Effect of aromatherapy on patients with Alzheimer's disease. Psychogeriatrics, 9, 173-179. http://dx.doi.org/10.1111/j.1479-8301.2009.00299.x

Kellerova, E., \& Delius, W. (1969). Unterschiede der vasomotorischen reaktivitat im muskel- und akralen hautgefassgebiet der oberen und unteren extremitaten. Zeitschrift fur Kreislaufforschung, 58, 917-925.

Kikuchi, A., Yamaguchi, H., Tanida, M., Abe, T., \& Uenoyama, S. (1992). Effect of Odours on Cardiac Response Patterns and Subjective States in a Reaction Time Task. Tohoku Psychologica Folia, 51, 74-82.

Klemm, W. R., Lutes, S. D., Hendrix, D. V., \& Warrenburg, S. (1992). Topographical EEG Maps of Human Responses to Odors. Chemical Senses, 17, 347-361. http://dx.doi.org/10.1093/chemse/17.3.347

Kyle, G. (2006). Evaluating the Effectiveness of Aromatherapy in Reducing Levels of Anxiety in Palliative Care Patients: Results of a Pilot Study. Complementary Therapies in Clinical Practice, 12, 148-155. http://dx.doi.org/10.1016/j.ctcp.2005.11.003

Lang, P. J., Bradley, M. M., \& Hamm, A. O. (1998). Emotion and Motivation: Measuring Affective Perception. Journal of Clinical Neurophysiology, 15, 397-408. http://dx.doi.org/10.1097/00004691-199809000-00004

Li, W., Howard, J. D., Parrish, T. B., \& Gottfried, J. A. (2008). Aversive Learning Enhances Perceptual and Cortical Discrimination of Indiscriminable Odor Cues. Science, 319, 1842-1845. http://dx.doi.org/10.1126/science.1152837

Libert, J.P., Candas, V., \& Vogt, J.J. (1978). Sweating response in man during transient rises of air temperature. J Appl Physiol., 44, 284-290.

Lin, P.W., Chan, W.C., Ng, B.F., Lam, L.C. (2007). Efficacy of aromatherapy (Lavandula angustifolia) as an intervention for agitated behaviours in Chinese older persons with dementia: a cross-over randomized trial. Int $J$ Geriatr Psychiatry, 22, 405-410. http://dx.doi.org/10.1002/gps.1688

Linkert, R. (1932). A Technique for the Measurement of Attitudes. Archives of Psychology, 140, 44-53.

Lledo, P.-M., Gheusi, G., \& Vincent, J.-D. (2005). Information Processing in the Mammalian Olfactory System. Psysiological Reviews, 85, 281-317. http://dx.doi.org/10.1152/physrev.00008.2004

Lorig, T. S., \& Schwartz, G. E. (1988). Brain and Odor: I. Alteration of Human EEG by Odor Administration. Psychophysiology, 16, 281-284.

Manley, C. H. (1993). Psychophysiological Effect of Odor. Critical Reviews in Food Science and Nutrition, 33, 57-62. http://dx.doi.org/10.1080/10408399309527612

Mehrabian, A., \& Russell, J. A. (1974). An Approach to Environmental Psychology. Cambridge, MA: MIT Press. 
Mombaerts, P. (1999). Molecular Biology of Odorant Receptors in Vertebrates. Annual Review of Neuroscience, 22, 487-509. http://dx.doi.org/10.1146/annurev.neuro.22.1.487

Morris, E. T. (1984). Fragrance. New York: Scribners.

Nadel, E.R., Bullard, R.W., Stolwijk, J.A.J. (1971). Importance of skin temperature in the regulation of sweating. J Appl Physiol., 31, 80-87.

Oberle, J., Elam, M., Karlsson, T., \& Wallin BG. (1988). Temperature-dependent interaction between vasoconstrictor and vasodilator mechanisms in human skin. Acta Physiol Scand., 132, 459-469. http://dx.doi.org/10.1111/j.1748-1716.1988.tb08353.x

Oka, T., Hayashida, S., Kaneda, Y., Takenaga, M., Tamagawa, Y., Tsuji, S., \& Hatanaka, A. (2008). Green Odor Attenuates a Cold Pressor Test-Induced Cardiovascular Response in Healthy Adults. BioPsychoSocial Medicine, 2, 2. http://dx.doi.org/10.1186/1751-0759-2-2

Oka, T., Oka, K., \& Hori, T. (2001).Mechanisms and Mediators of Psychological Stress-Induced Rise in Core Temperature. Psychosomatic Medicine, 63, 476-486. http://dx.doi.org/10.1097/00006842-200105000-00018

Perry, N., \& Perry, E. (2006). Aromatherapy in the Management of Psychiatric Disorders: Clinical and $\begin{array}{lllll}\text { Neurophamacological } & \text { Perspectives. } & \text { CNS } & \text { Drugs, } & 20,\end{array}$ http://dx.doi.org/10.2165/00023210-200620040-00001

Price, S., \& Price, L. (2007). Aromatherapy for Health Professionals (3rd ed.). London: Elsevier.

Raudenbush, B., Grayhem, R., Sears, T., \& Wilson, I. (2009). Effects of Peppermint and Cinnamon Odor Administration on Simulated Driving Alertness, Mood and Workload. North American Journal of Psychology, 11, 245-256.

Roddie, I. C. (1983). Circulation to Skin and Adipose Tissue. In J. T. Shepard, \& F. M. Abbound (Eds.), Handbook of Physiology. The Cardiovascular System (Vol. II, Part 1, Chapter 10, pp. 285-317). Bethesda, MD: American Physiological Society.

Roddie, I. C., Shepherd, J. T., \& Whelan, R. F. (1957). The Contribution of Constrictor and Dilator Nerves to the Skin Vasodilatation during Body Heating. The Journal of Physiology, 136, 489-497. http://dx.doi.org/10.1113/jphysiol.1957.sp005775

Rowell, L. B. (1981). Active Neurogenic Vasodilation in Man. In P. M Van Houtte, \& I. Leusen (Eds.), Vasodilation (pp. 1-17). New York: Raven Press.

Satoh, T., \& Sugawara, Y. (2003). Effects on Humans Elicited by Inhaling the Fragrance of Essential Oils: Sensory Test, Multi-Channel Thermometric Study and Forehead Surface Potential Wave Measurement on Basil and Peppermint. Analytical Sciences, 19, 139-146. http://dx.doi.org/10.2116/analsci.19.139

Smallwood, J., Brown, R., Coulter, F., Irvine, E., \& Copland, C. (2001). Aromatherapy and Behaviour Disturbances in Dementia: A Randomized Controlled Trial. International Journal of Geriatric Psychiatry, 16, 1010-1013. http://dx.doi.org/10.1002/gps.473

Sugawara, Y. (2001). Odor Distinctiveness between Enantiomers of Linalool. Current Topics in Analytical Chemistry, 2, 201-210.

Sugawara, Y. (2008). Sensory Profiling for Verbal Responses in Perceived Odor Quality in Humans. In L. N. Piccard (Ed.), Biological Psychology: New Research (Chapter 4, pp. 145-165). New York: Nova Science Publishers.

Sugawara, Y., \& Kawasaki, M. (2000). Skin Temperature Change Elicited by Inhalation of the Fragrance of Essential Oils in Relation to Mental Work: Multi-Channel Thermometric Study on Basil and Peppermint. Journal of Home Economics of Japan, 51, 675-681.

Sugawara, Y., Fukui, H., Shigeoka, C., Hasegawa, R., \& Okimoto, A. (2006). Multichannel Thermometric Study of Skin Temperature Changes in Humans While Inhaling Essential Oils. Flavour and Fragrance Journal, 21, 416-422. http://dx.doi.org/10.1002/ffj.1683

Sugawara, Y., Hara, C., Aoki, T., Sugimoto, N., \& Masujima, T. (2000). Odor Distinctiveness between Enantiomers of Linalool: Difference in Perception and Responses Elicited by Sensory Test and Forehead Surface Potential Wave. Chemical Senses, 25, 77-84. http://dx.doi.org/10.1093/chemse/25.1.77

Sugawara, Y., Hara, C., Tamura, K., Fujii, T., Nakamura, K., Masujima, T., \& Aoki, T. (1998a). Sedative Effect on Humans of Inhalation of Essential Oil of Linalool: Sensory Evaluation and Physiological Measurements Using Optically Active Linalools. Analytica Chimica Acta, 365, 293-299. 
http://dx.doi.org/10.1016/S0003-2670(97)00639-9

Sugawara, Y., Hino, Y., Kawasaki, M., Hara, C., Tamura, K., Sugimoto, N., Yamanishi, U., Miyauchi, M., Masujima, T., \& Aoki, T. (1999). Alteration of Perceived Fragrance of Essential Oils in Relation to Type of Work: A Simple Screening Test for Efficacy of Aroma. Chemical Senses, 24, 415-421. http://dx.doi.org/10.1093/chemse/24.4.415

Sugawara, Y., Maruyama, S., Nakagawa, N., Yamada, E., Seto, M., Sumihiro, S., Aoi, N., Nishimoto, M., Kobayashi, Y., \& Hirano, M. (2008). Verbal and Non-Verbal Responses to Odorants in Humans While Inhaling the Fragrance of Peppermint and Spearmint Essential Oils and Linalool. International Journal of Essential Oil Therapeutics, 2, $111-121$.

Sugawara, Y., Nishimoto, M., Kobayashi, Y., Hasegawa, R., Okimoto, A., \& Aoki, T. (2003). Repeatability of the Measure Required for Perceptional Changes of the Fragrance of Essential Oils Was Tested in Terms of Sensory Evaluation Spectrums. Bull. Fac. Human Life Environ. Sci. Hiroshima Women's Univ., 9, 21-36.

Sugawara, Y., Shigetho, A., Yoneda, M,, Tuchiya, T., Yamada, H., Matumura, T., \& Hirano M. (2015). Relationship between mood change, odour and its physiological effects in humans in terms of the Sensory evaluation spectrum. Psychology, 6, 965-988. http://dx.doi.org/10.4236/psych.2015.68095

Sugawara, Y., Shigetho, A., Yoneda, M., Tuchiya, T., Matumura, T., \& Hirano, M. (2013). Relationship between Mood Change, Odour and Its Physiological Effects in Humans While Inhaling the Fragrances of Essential Oils as Well as Linalool and Its Enantiomers. Molecules, 18, 3312-3338. http://dx.doi.org/10.3390/molecules18033312

Sugawara, Y., Sugimoto, C., Minabe, S., Iura, Y., Okazaki, M., Nakagawa, N., Seto, M., Maruyama, S., Hirano, M., \& Kitayama, I. (2009). Use of Human Senses as Sensors. Sensors, 9, 3184-3204. http://dx.doi.org/10.3390/s90503184

Sugawara, Y., Tomota, T., \& Tamura, K. (1998b). Perceived Fragrance of Essential Oils in Relation to Type of Work. Journal of Home Economics of Japan, 49, 1281-1290.

Sugenoya, J., Ogawa, T., Jmai, K., Ohnishi, N., Natsume, K. (1995). Cutaneous vasodilatation responses synchronize with sweat expulsions. Eur J Appl Physiol., 71, 33-40.

Torii, S., Fukuda, H., Kanemoto, H., Miyauchi, R., Hamauzu, Y., \& Kawasaki, M. (1988). Contingent Negative Variation and the Psychological Effects of Odour. In S. van Toller, \& G. H. Dodd (Eds.), Perfumery: The Psychology and Biology of Fragrance, 107-120. New York: Chapman Hall. http://dx.doi.org/10.1007/978-94-017-2558-3_6

Vallbo, A. B., Hagbarth, K.-E., Torebjork, H. E., \& Wallin, B. G. (1979). Somatosensory, Proprioceptive and Sympathetic Activity in Human Peripheral Nerves. Physiological Reviews, 59, 919-957.

Valnet, J. (1982). The Practice of Aromatherapy. Saffron Walden, MA: C W Daniel Company.

Wurster, R.D., \& McCook, R.D. (1969). Influence of rate of change in skin temperature on sweating. J Appl Physiol., 27, 237-240.

Yamagata, Y., \& Sugawara, Y. (2014). Sensory Evaluation Spectrum Method as a Descriptive Sensory Analysis. Psychology, 5, 1591-1610. http://dx.doi.org/10.4236/psych.2014.514170

Yamaguchi, H. (1990). Effect of Odor on Heart Rate. In M. Indo (Ed.), The Psychophysiological Effects of Odor, Aromachology (p. 168). Tokyo: Koryo.

Yamakoshi, T., Yamakoshi, K., Tanaka, S., Nogawa, M., Shibata, M., Sawada, Y., Rolfe, P., \& Hirose, Y. (2007). A Preliminary Study on Driver's Stress Index Using a New Method Based on Differential Skin Temperature Measurement. $29^{\text {th }}$ Annual International Conference of the IEEE Engineering in Medicine and Biology Society, Lyon, 22-26 August 2007, 722-725. http://dx.doi.org/10.1109/iembs.2007.4352392

Yoshida, I., \& Mori, K. (2007).Odorant Category Profile Selectivity of Olfactory Cortex Neurons. The Journal of Neuroscience, 27, 9105-9114. http://dx.doi.org/10.1523/JNEUROSCI.2720-07.2007

Zhang, X., \& Firestein, S. (2002).The Olfactory Receptor Gene Superfamily of the Mouse. Nature Neuroscience, 5, 124-133.

Ziegler, L. H., \& Cash, P. T. (1938). A Study of the Influence of Emotions and Affects on the Surface Temperature of the Human Body. The American Journal of Psychiatry, 95, 677-696. http://dx.doi.org/10.1176/ajp.95.3.677

\section{$(c c)$ BY}

This work is licensed under a Creative Commons Attribution 3.0 License. 